\title{
Patent Production at a European Research University: Exploratory Evidence at the Laboratory Level
}

\author{
Joaquín M. Azagra-Caro a , Nicolas Carayol ${ }^{\text {b }}$, Patrick Llerena ${ }^{\text {b, * }}$ \\ ${ }^{a}$ Institute of Innovation and Knowledge Management (INGENIO), Universidad Politécnica \\ de Valencia-CSIC, Valencia, Spain \\ ${ }^{\mathrm{b}}$ Bureau d'Economie Théorique et Appliquée (BETA), Université Louis Pasteur, Strasbourg, \\ France \\ * Corresponding author: Patrick LLERENA, BETA, 61 avenue de la Foret Noire, 67087 \\ Strasbourg, France, e-mail: pllerena@cournot.u-strasbg.fr
}




\begin{abstract}
Most studies of academic patenting focus on the university as the unit of analysis. In contrast, we examine this phenomenon at the laboratory level. Based on a sample of 83 research laboratories of University Louis Pasteur (ULP, Strasbourg, France) from 1993 to 2000, we constructed a panel data set that allows us to discriminate between patents that are owned by the university and those that are owned by firms and other organizations but invented by faculty members. We use these data to estimate a patent production function and we have three main findings. First, ULP owned patents respond to public funding but not to time shocks like in US. Second, disciplines and institutions matter to estimate the impact of contractual funding on university patents, validating the laboratory approach. Third, university-non-owned patents behave different from university owned patents, e.g. they are more responsive to industrial funding or institutional prestige.
\end{abstract}

JEL classification: O31, O32, O34, O38, O39 


\section{Introduction}

In recent decades, we have witnessed several fairly disruptive changes in the regulatory environment for university-industry technology transfer (Bayh-Dole Act and European derivatives), and for the definition of academic research goals (increase in publication requirements, rise of the patenting activity). This observation applies to funding regimes (shortening of public funding, evolving rationales for funding) especially in today's European context not only because national funding systems are evolving but also because European public support (with its own rationale) is becoming more significant. One may also notice that contractual funding ${ }^{1}$ becomes increasingly important as compared to the usual recurrent funding. Contractual funding is often acknowledged as being less neutral on the definition of academics' research agendas. Some authors thus emphasize serious risks to see a decrease of the relative importance of fundamental research. They also consider the possible unintended consequences on the speed of disclosure and dissemination of findings (for evidence on these issues see Cohen et al. 1994, 1998; Blumenthal et al. 1996, 1997). In that respect, one major event in the near past is the dramatic increase in university patenting (Henderson et al., 1998; Nelson 2001; Mowery and Ziedonis, 2002). While scholars still argue about the risks and opportunities generated by patenting at universities (Pavitt, 1998; Rappert et al., 1999; Mowery and Sampat, 2001), one may acknowledge that little is known about the mechanisms which favor faculty patenting. In particular, there is no systematic evidence that industrial funding increases faculty invention behavior.

In this paper, we intend to analyze the determinants of academic patenting. Among the determinants considered, we include all contractual funding decomposed by source thereby departing from other studies on academic patenting ${ }^{2}$. Thus, the study addresses two more specific questions: To what extent do university patents respond to the increase of contractual funding? What kind of contractual funding (local public, national public, European, or private) enhances academic patenting more?

Our data cover the period 1993-2000 and concern the research activity of 83 active academic laboratories on which we have reliable and complete information over the period. The laboratories 
belong to one single university, namely Louis Pasteur University (ULP) of Strasbourg. This university is quite large, diversified, has an old tradition of fundamental research and a long standing of scientific excellence. The Third European Report on Science and Technology Indicators (2003) ranks it first among French universities in terms of impact and 11th among European universities.

In this respect our approach also differs from previous econometric studies which focused on the university level of analysis. Thus a unique feature of our study is that we are analyzing data at the laboratory level. The laboratory level has been emphasized as the relevant level of analysis of scientific activity (Stephan, 1996, Arora et al. 1998). That is especially true in the (continental) European context and surely when the aim is to deal with funding issues: The laboratory is the locus of collective coordination for buying and sharing research facilities, for sharing revenues from intellectual property ${ }^{3}$ and for defining research aims (Crow and Bozeman, 1987). The laboratory level also allows us to control for disciplinary differences and for some institutional features. Finally, another important contribution of our study which was linked to European specificities is that it includes not only patents owned by the university but also all patents invented by at least one permanent researcher of the university.

The paper is structured as follows: Section 2 summarizes the determinants of university patenting as analyzed in the existing literature and argues how we shall contribute to it. Section 3 presents the model we want to test and the sample we use. Section 4 includes the estimation results. Section 5 concludes and indicates further research lines.

\section{The determinants of university patents}

\subsection{The determinants of US aggregate university owned patents: valid for a single European research university?}

Scholars initially focused on the observation of the recent sharp increase in university patenting and on the factors that may have caused such phenomena. Henderson et al. (1998) indicate three of these factors in the US case. The first one is connected to the legal framework: Major changes of the federal law after the Bayh-Dole Act in the early 80's allowed universities to retain the property rights derived 
from federally funded research ${ }^{5}$. Meyer-Krahmer and Schmoch (1998) and Pavitt (1998) argue that the legal and financial framework are one justification for national differences in university patenting. Secondly, the growing industrial funding of university research may have upsurge of the number of patents. The last factor resides in the substantial increase of technology transfer facilities at universities: technology transfer offices (TTO) encourage faculty patenting in order to facilitate further interactions with industry ${ }^{6}$.

More recently, the literature began to focus on the relationship between R\&D expenditures and patents by extending the techniques initiated by Griliches (1990) in the case of firms to universities. In that respect, the seminal work of Adams and Griliches (1998) on academic research output functions has been a starting point for the following studies (even if they are using publications as outputs).

We found five works that apply econometric techniques to estimate the relation between university patents and different explanatory variables in the US case:

* Payne and Siow (2003) concentrate on the effect of federal funding on four research outputs, including granted patents. They use panel data of 74 US research universities (53 in the case of patents) over the period 1972-1998 (1975-1994 in the case of patents). They apply OLS and IV regression models (plus a Tobit in the case of patents), controlling for university and time effects.

* Foltz et al. (2000) focus on the case of university patents in agricultural biotechnology, but they also build a model for all patents. With a cross-section of 142 US universities, they apply a zero inflated negative binomial model.

* In a later work, Foltz et al. (2001) add some dynamic variables but restricting themselves to agricultural biotechnology patents. They use data from 127 universities over the period 19911998, forming a panel of 561 observations, and run a random effect negative binomial regression.

* Coupé (2003) applies Poisson and negative binomial regressions on a cross-section of some 500 US universities in 1994 and on a panel of 212 universities and 23 years (from 1972 to 1994). He uses not only patent counts but also patent citations as an output.

* Carlsson and Fridh (2002) run a survey in 12 US universities to understand the functioning of TTO and their role in patenting and licensing activities, start-ups and industry-sponsored research $^{8}$. It allows them to build a conceptual model of the process of technology transfer, which 
they split into several models (according to the different steps and outputs). These models are also estimated on the larger sample of the AUTM survey (170 universities over 1991-1996).

This is a summary of their results with regards to some independent variables:

* R\&D expenditure: Carlsson and Fridh (2002) use an aggregate measure of R\&D expenditure. They find a significant positive impact on the number of disclosure, on which the number of patent applications depends. Payne and Siow (2003) and Coupé (2003) focused on federal public R\&D expenditure and Foltz et al. $(2000,2001)$ also analyze other sources of funding:

Public funding: with regards to federal funding, Payne y Siow (2003) find a positive impact on patents, but significance varies according to the specification. Overall, they conclude that the returns of university R\&D to patents are decreasing, as in the case of firms. Coupé (2003) reaches a similar conclusion. Foltz et al. (2000) use the sum of federal and state funding and they find it positive and significant for all university patents but not significant for agricultural biotechnology university patents. Foltz et al. (2001) decompose the sum of both sources and they find that state funding has a positive, significant, influence on agricultural biotechnology university patents while federal funding has not.

Industrial funding: Foltz et al. (2000) do not find it significant in any model. Foltz et al. (2001) ratify that result.

D Other funding: Foltz et al. (2000) do not find the sum of own funding plus other funding significant on all university patents but significant on agricultural biotechnology university patents. Foltz et al. (2001) decompose the sum of both sources and they find that own funding has a positive, significant, influence on agricultural biotechnology university patents while other funding has not.

$>$ In sum, it seems that the closer to the local level, the higher the impact of public funding, with decreasing returns to scale, whereas funding from the rest of sources is not significant.

Size: Payne y Siow (2003) measure it through the number of faculty and they do not find it significant. The same happens to Foltz et al. (2001). On the other hand, Coupé (2003) finds it significant. However, the same author uses a second measure, the number of alumni, that he does not find significant. Overall, the evidence on size is not conclusive. 
Trend: Coupé (2003) finds it positive and significant. It implies the existence of exogenous time shocks, from the point of view of research units within university, to be attributed to the next variables.

Strength of TTO: Foltz et al. (2000) measure it through the number of employees of the TTO and they find that it matters positively and significantly (although with decreasing returns to scale. On turn, Foltz et al. (2001) find that this measure is not significant, while a measure of the quality of the TTO (the ratio between number of patent applications by number of disclosures) is positive and significant. On the other hand, Coupé (2003) includes a dummy variable indicating the year of establishment of the TTO at the university, finding a positive and significant influence. The same happens to Carlsson y Fridh (2002) with the number of disclosures, on which the number of patent application depends. They also find the influence of the number of TTO employees significant and positive.

University R\&D spillovers: Coupé (2003) includes a measure of aggregate R\&D of other universities but the own and he finds its impact positive and significant. He attributes it to knowledge externalities.

Legal framework: Coupé (2003) uses a dummy variable to measure the legal change represented by the Bayh-Dole Act, without a significant effect. ${ }^{\mathrm{i}}$

We wonder whether the study of a single university at laboratory level may show similar results about R\&D expenditure, number of faculty and time shocks. With regards to R\&D expenditure, however, descending to laboratory level also gives the chance to collect micro-data on other contractual funding. If we consider patents as the output of a production function where capital is a factor, we may consider all types of funding, not only R\&D expenditure, as able to generate patents. Moreover, this allows us to decompose funding with respect to the source of funding and thus to track which sources of funding may or may not sustain patent production at the micro level. Taking into account these considerations, this is the first hypothesis we want to test:

H1: the higher the amount of contractual funding, the higher number of university owned patents.

There are two extensions of this hypothesis:

H1a: regional and local public funding has the largest impact among contractual funding. 
H1b: returns to scale of significant contractual funding are decreasing.

Besides, regarding size and time shocks, we may set these two hypotheses:

H2: the higher the number of faculty, the higher number of university owned patents.

H3: as time goes by, the number of university owned patents increase.

\subsection{Further determinants of university owned patents: using laboratories as a unit of analysis}

The second dimension in which we intend to contribute to the existing literature has to do with the unit of analysis. As the literature review shows, the university is the most common unit of observation retained for explaining patent production. To the best of our knowledge the only studies concerned with academic patenting that looked inside the university are the ones of Wallmark (1997), Agrawal and Henderson (2002) and Azagra et al. (2003). Nevertheless, the first study does not provide econometric analysis and the second one is more concerned with the relationship between publications and patents. Just the third one has a similar approach to ours.

Universities are certainly composed of heterogeneous research units that vary in several respects (types of scientific production, funding structure, homogeneity of research themes, modes of coordination, etc.) that may strongly affect patent production. In this respect, the organization of research at French universities is strongly based on laboratories ${ }^{12}$ (Joly and Mangematin, 1996). The prevalent organization of research in US universities which is based on a high level of autonomy given to Principal Investigators is not to be found as such in the French system. This institutional context (far from being a methodological constraint) offers us an opportunity to go down to the micro level of research activities (i.e. laboratory). Laboratories can be classified by discipline and institutional diversity which thus makes it possible to test some of the micro-determinants of academic patenting which have only been considered by appreciative studies but not by econometric ones.

* Disciplines: it is widely accepted that university owned patents in US is a phenomenon of a number of disciplines, e.g. on the one hand life sciences in a broad sense (chemistry, drugs, biotechnology) and on the other hand, information and communication technologies (Henderson et al., 1998, Jaffe, 2000). However, according to national idiosyncrasies (Pavitt, 1998), there might 
be some other leading disciplines in patenting e.g. mechanical engineering in Germany (MeyerKrahmer y Schmoch, 1998). For single universities, the distribution by patenting disciplines may be homogenous, e.g. Chalmers University of Technology (Wallmark, 1998). On the other hand, there are disciplines such as social sciences and humanities that do not produce physical technologies and thus are not likely to apply for patents, or other with legal restrictions to patent (e.g. mathematics or software).

* Institutions: higher levels of prestige are associated to university patenting at university level (MIT concentrates owns $8 \%$ of total US university owned patents, Henderson et al., 1998; scientific ranking has a positive significant effect, Foltz et al., 2000). The same is true at individual level (two star researchers invented $25 \%$ of Chalmers University of Technology patents). Evidence at institutional level would be particularly relevant in European countries, where there is a trend for universities to attract or create joint research units with their respective National Research Councils (e.g. CNRS in France, CSIC in Spain, CNR in Italy).

All these considerations recommend the use of disciplines and institutions in an econometric estimation -possible at the laboratory level. Besides, there is the important econometric question whether R\&D expenditure or contractual funding is significant after controlling for different disciplinary and institutional propensities to patent. The only study doing so is Azagra et al. (2003), who find a significant higher propensity of science-based disciplines and prestigious institutions to hold university owned patents in the case of a Spanish polytechnic university, and contractual funding still relevant after that. In single sentences, we want to test these hypotheses:

H4: life sciences show a higher propensity to produce university owned patents than other disciplines. H5: more prestigious institutions tend to produce more university owned patents than less prestigious institutions. 


\subsection{Determinants of university non-owned patents: the need for a European viewpoint}

One may notice that the econometric studies presented in section 2.1 have concentrated on US universities whereas university patenting in Europe may exhibit some important idiosyncrasies that should be taken into consideration in a policy perspective. ${ }^{10}$

For instance, the focus on US evidence has left aside the patents invented by faculty members but not owned by the university. Indeed, Meyer (2003) and Saragossi and van Pottelsberghe de la Potterie (2003) point out that, in Europe, the set of patents invented by university researchers is much broader than the set of patents their universities own. The contrast with the US situation comes from the high variety in the regulatory environments that face European universities. In France for instance, there was no need for a Bayh-Dole Act because institutions always had the right to take intellectual property on publicly funded research. Nevertheless, the public research system had until very recently little institutional concern for retaining intellectual property rights. Independently of the legal framework per se universities usually did to retain these rights which were often considered as "counterproductive" in terms of knowledge diffusion or for attracting industrial funding.

Consequently, our aim is to study university non-owned patents. Actually, we may distinguish two other groups within these patents: first, patents invented by faculty who also invented university owned patents, so-called "first circle of inventors"; second, patents invented by faculty who never invented university owned patents, so-called "second circle of inventors". A priori, we may not exclude that different forces determine each type of patents. Hence, these are the hypotheses we want to test:

H6: the determinants of university owned patents invented by inventors of the first circle are those of university non-owned patents invented by inventors of the first circle.

H7: the determinants of university owned patents invented by inventors of the first circle are those of university non-owned patents invented by inventors of the second circle. 


\section{Methodology and data}

We use data about laboratories of University Louis Pasteur (ULP) in Strasbourg (France) which is a quite large and diversified university. It comprises seventeen separate institutional components (i.e. schools, education/training and research units, and various institutes) located in six campuses in the Strasbourg area in which around 18,000 students are enrolled. Research and teaching at the university cover a wide range of disciplines. These disciplines exclude humanities and social sciences (except economics, management and geography). ULP has an old tradition of fundamental research and a long standing of scientific excellence. Its researchers received numerous national and international scientific prizes, including the still active Nobel Prize laureate for Chemistry Jean-Marie Lehn (1987) for his contribution to the field of Supramolecular Chemistry. Altogether, the University Louis Pasteur is one of the largest French universities in terms of research. According to the Third European Report on Science \& Technology Indicators (2003, p.311), it is the best French University in terms of impact and the eleventh European one. Such a research capacity is sustained by its close links with major national research institutions such as the Centre National de la Recherche Scientifique (from now CNRS, National Center for Scientific Research) and the Institut National de la Santé et de la Recherche Médicale (from now INSERM, National Institute for Health and Medical Research).

\subsection{Dependent variables and econometric model}

We plan to estimate a patent production function where the dependent variable is patent applications with at least one inventor from ULP. Our data on patents comes originally from the French Institute of Intellectual Property (INPI). We had a list of all the teaching and research staff of ULP active in 1996 and $2000^{14}$. Through different queries, we identified French, European and PCT patent applications in which at least one person in the former list appeared as an inventor ${ }^{15}$. Some inventors appeared in both ULP-owned patents and ULP non-(co-)owned patents and some others just in ULP non-(co-)owned patents. Those were identified as inventors of the first and the second circle, respectively. Therefore, we can subdivide patents into three types:

* Patown: ULP owned or co-owned patents -from now on (co-)owned patents, by definition invented by the first circle of inventors. 
Patnon_own1: ULP non-(co-)owned patents invented by the first circle of inventors.

Patnon_own2: ULP non-(co-)owned patents invented by the second circle of inventors.

Again, it is interesting to differentiate the three variables because each one may reflect different institutional frames and/or behavior concerning the necessity or the usefulness of patent applications. Figure 1 tries to clarify the relation between the three types of ULP patents.

Figure 1. Types of ULP patents

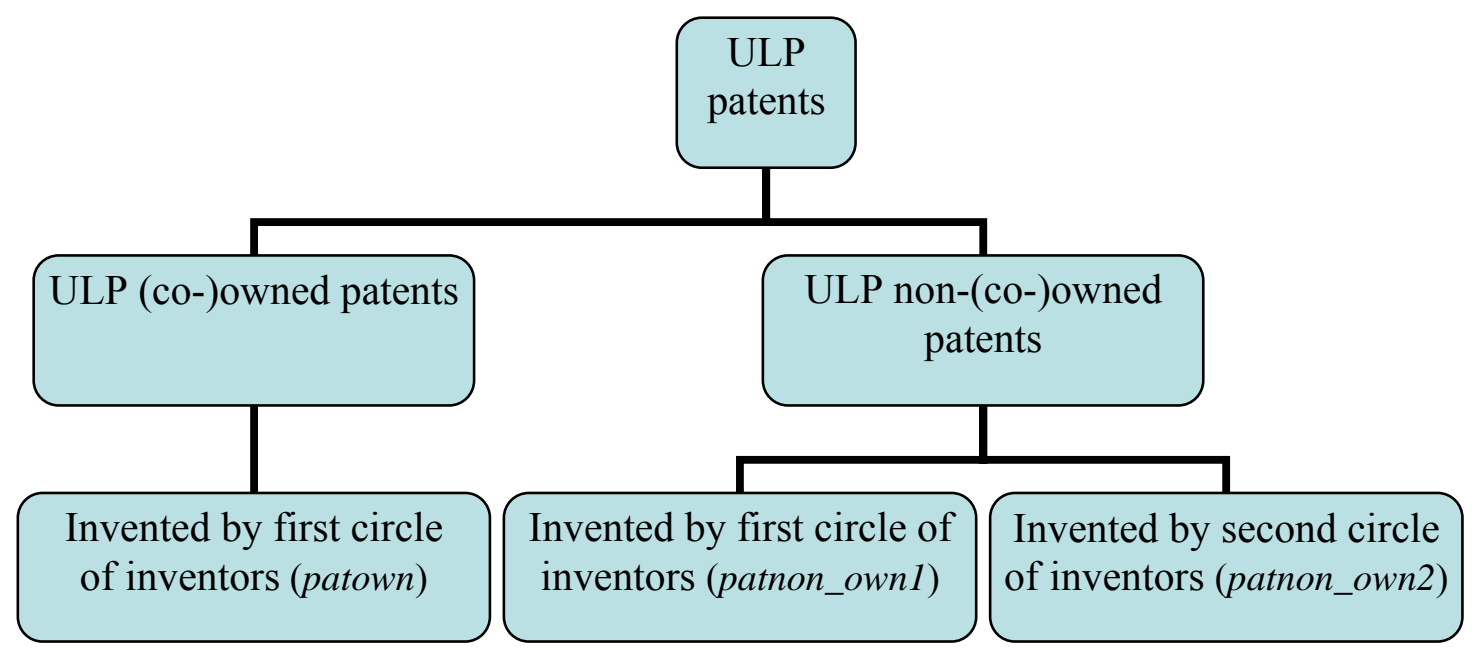

In order to set an adequate econometric framework, we must take into account that patents can only take non-negative integer values. When we try to explain them as a function of a variable measured in monetary terms, such as contractual funding, estimation by least squares is usually not appropriate. Instead, count data methods, as proposed by Hausman et al. (1984), are more relevant. The most immediate method is the Poisson estimation, which models the patent variable as the outcome of a Poisson process, but imposes on the distribution the restriction that the mean and the variance of the observations are equal. More sophisticated, negative binomial estimation adds a parameter to the Poisson specification to control for the possibility that this assumption does not hold. Finally, zero inflated negative binomial estimation adds a second parameter to allow the observations to be the result of two possible distributions: one where zero values reflect a voluntary decision not to produce a positive outcome and another one where zero values reflect the impossibility of getting a different outcome $e^{\text {ii }}$. 


\subsection{Independent variables}

Data on contractual funding, institutional characteristics and teaching and research staff were built specifically for this project from internal sources of ULP, mainly from its industrial liaison office (ILO) and the financial department of the university. An important specificity of the database is that we consider only research units which have decided (and most of the time succeeded) to undergo an evaluation process, to be recognized by central authorities such as the Ministry of Research and/or the CNRS and/or the INSERM. In the same way, the teaching and research personnel considered consists of members "listed" by the research units themselves. However, in the case of ULP, the data base includes almost all the existing research units at the university and the great majority of available teaching and research staff doing research. The list of variables and their description is the following:

* Cont: logarithm of the value of contractual funding, deflated by the GDP deflator. We lag it one period to prevent endogeneity with patents as much as possible Contractual funding includes R\&D contracts, some service contracts (consultancies are excluded), grants, etc. We can differentiate the following variables, by source of funding, all measured in logarithm of real value ${ }^{18}$ :

$>$ Nat: value of contracts with national government

$>$ Reg: value of contracts with regional or local governments

$>$ Eur: value of contracts with European government

Ind: value of contracts with industry

$>\operatorname{Prc}$ : value of contracts with public research centers

$>$ As: value of contracts with associations

* Dcont: dummy variable equal to 1 in year $t$ if the laboratory is a CNRS or INSERM unit and it reports no contracts that year $t$, which means that their contracts are managed by those institutions (and not by ULP). We build this variable because an important limitation of the data on contracts is that some of the laboratories in the sample are units belonging at least partially to other public research organizations, such as CNRS or INSERM. These laboratories have some degree of freedom to locate the management of their research contracts in either of their parent organizations. As a result of this specific institutional aspect, we had no information about contracts managed outside ULP ${ }^{16}$. 
* Size: size categories, ranging from 0 to 3 , according to the number of researchers. While data on contracts are time series, data on laboratories and teaching staff are available only for a single year, $1996^{17}$. Thus, we could not build a dynamic variable for size but a static variable that we assume to be constant over time. In order to reduce the problem, we did not measure the variable through actual size but through four size categories, delimited by the quartiles of the distribution. We believe that this categorization is eventually more stable.

* Disc: a series of dummies for the main disciplines at ULP: bio (biology), che (chemistry), gen (genetics), med (medicine), neu (neurology), ph (physics) and others -the benchmark, containing other exact sciences (apart from physics) and social sciences and humanities. This variable and the next one about the type of laboratory are based on official classifications. Both are time-invariant.

* Inst: a series of dummies for types of research units at ULP: uins (unité INSERM, or INSERM unit), upr (unité propre de recherche, or research unit which are strongly attached to CNRS), umr (unité mixte de recherche, or joint research unit, i.e. ULP-CNRS or ULP-INSERM) and others (benchmark) It should be noted that this classification is linked to the institutional recognition of the unit. While the benchmark represents laboratories labeled only by the French Ministry of Science and Technology, the first three are also recognized by CNRS or INSERM and get extra funding from them. The recognition by a National Public research institution like CNRS or INSERM is the result of a stronger scientific evaluation process of the research outputs, at least every four years. Therefore recognition by CNRS and/or INSERM is often a strong signal of scientific (and academic) quality.

* Time: a trend that captures exogenous forces affecting all laboratories (e.g. strength of TTO, contractual funding spillovers and legal changes) and hence laboratory- invariant ${ }^{\mathrm{iii}}$.

We have classified patents according to the laboratory to which the inventors belong. Matching the different databases induced the selection of the 8 years running from 1993 to 2000 as a period of observation. Our information covers the 83 laboratories existing in 1996. We assume them to have been in existence during the whole period (the assumption is relatively realistic, the research structure of the university being stable during the period). The final panel has then 664 observations. 


\subsection{Descriptive statistics and selection technique}

Table 1 provides some descriptive statistics (mean and standard error) of the variables. The fifth column indicates the distribution of the number of patents according to our categories of laboratories.

The total number of patents is 463 , which means on average every laboratory applied for 0.70 patents per year. ULP owns only 62 of those (mean 0.09), firms and other institutions own 153 from the first circle of inventors (mean 0.23) and 248 from the second circle of inventors (mean 0.37).

The total amount of contracts adds up to $67,454,230 €$ and the average is $101,588 €$ (values in the table are measured in logs). $24 \%$ of the observations are both zeros and reported by CNRS or INSERM laboratories ${ }^{\text {iv }}$. The number of teaching and research staff in 1996 was 1,400 , which means that the average laboratory had 17 researchers, a value between our size categories 1 and 2 .

The predominant discipline at ULP is medicine ( $27 \%$ of the laboratories), followed by biology and genetics (14\% and $11 \%$ of the laboratories, respectively), i.e. $52 \%$ are related to life sciences in a broad sense. We can see in column 5 that the distribution of patents is somewhat different and much more concentrated. Medicine holds less than $8 \%$ of all applications, whereas genetics and biology hold $37 \%$ and $23 \%$, respectively. Even physics, with only $6 \%$ of all laboratories, holds $11 \%$ of the patents ${ }^{19}$.

The predominant types of laboratory are CNRS proper units (25\%) and CNRS/INSERM joint units (23\%). The correlation with patents is higher than in the case of disciplines, since CNRS upr units have most of them (55\%), followed by CNRS joint units (25\%). The distribution, though, is even more skewed than in the case of disciplines.

Before presenting the results of the estimations, we will explain the strategy we followed in order to discriminate among different count data models and select a reduced number of variables:

* We estimate a Poisson regression.

* If the Cameron-Trivedi test does not indicate overdispersion but the Vuong statistic indicates excess of zeros, we estimate a zero inflated Poisson regression.

* If the Cameron-Trivedi test indicates overdispersion, we estimate a negative binomial regression. We make a likelihood ratio test to test it against Poisson regression.

* If we prefer negative binomial regression and the Vuong statistic indicates excess of zeros, we estimate a zero inflated negative binomial regression. 
* Once selected the best technique, we delete the non-significant variable the coefficient of which has the worst t-value -in the case of a vector of dummy variables, we test their joint significance.

* We estimate a reduced model without the deleted variable. We make a likelihood ratio test against the original model.

* If the test shows preference for the reduced model, we repeat previous steps. If there are no nonsignificant variables to delete, we accept the reduced model.

We show the final reduced models in next section. Notice that negative binomial estimations were always preferred to Poisson ones. Zero inflated negative binomial model was preferred to ordinary negative binomial one only for ULP not (co-)owned patent invented by inventors of the first circle ${ }^{\mathrm{v}}$.

\section{Estimations}

Table 2 shows the results of estimating our models. The first column uses ULP (co-)owned patents invented by inventors of the first circle as a dependent variable. We can see that only a particular kind of public funding has a significant influence on patenting behavior: funding by regional or local authorities. It is apparently due to the "applied"-oriented nature of the projects funded by these sources. However, we need further investigation to understand this particular result. In any case, we find support for Hypotheses 1 (the higher the amount of contractual funding, the higher number of university owned patents) and 1a (regional and local public contractual funding has the largest impact on university owned patents). We tested separately whether the coefficient is significantly different from 1 and we cannot reject Hypothesis $1 \mathrm{~b}$ (returns to scale of significant contractual funding to university owned patents are decreasing).

The control variable for possible missing contractual funding is not significant, indicating that it is not an actual problem.

The coefficient of size is positive and significant as well, reflecting that it is important to control for this variable to estimate the effect of contractual funding. Given not conclusive evidence on the US case, we are not sure whether this constitutes a difference with other studies. Overall, we find support for Hypothesis 2 (the higher the number of faculty, the higher number of university owned patents). 
The time trend does not appear to be significant, thus the joint effect of external forces such as TTO, legal changes or funding spillovers may not be effective. Hence, we do not find support for Hypothesis 3 (as time goes by, the number of university owned patents increase).

The coefficients of several disciplinary dummies are significantly positive: biology, genetics and medicine. It means that the probability to produce ULP owned patents in these fields is higher than in others, the benchmark. Therefore, we find evidence to support Hypothesis 4 (life sciences show a higher propensity to produce university owned patents than other disciplines), at least for the three mentioned disciplines.

Regarding institutional differences, we can see that they are not significant to explain the dependent variable. Thus, we do not find support for Hypotheses 5 (more prestigious institutions tend to produce more university owned patents than less prestigious institutions).

Column 2 includes patents not (co-)owned by ULP but invented by inventors of the first circle those who also invented ULP (co-)owned patents. In contrast with the former, industrial funding is the only contractual funding which significantly influences the number of ULP not (co-)owned patents. It is due to the fact that, for research funded by industry, the results belong often the corresponding firm. Size is again positive and significant and the trend is not. Among disciplines, biology and genetics show a higher propensity as well, but not medicine, replaced instead by physics. Institutions become significant to explain the lower propensity to produce this kind of patents of two more prestigious institutions.

With regards to Hypothesis 6 (the determinants of university owned patents invented by inventors of the first circle are those of university non-owned patents invented by inventors of the first circle), we find some evidence to support it in the case of returns to contractual funding, size, time and some disciplines (biology and genetics), but not in the case of the type of contractual funding, some disciplines (medicine and physics) and institutions.

Column 3 includes patents not (co-)owned by ULP and invented by inventors of the second circle those who did not invent any ULP (co-)owned patents. Opposite to the two former models, no contractual funding is significant. On the other hand, once again, size is positive and significant and the trend is not. No discipline stands out positively but medicine and biology show a lower propensity 
to patent through inventors of the first circle. On the contrary, more prestigious institutions show a clear higher propensity.

With regards to Hypothesis 7 (the determinants of university owned patents invented by inventors of the first circle are those of university non-owned patents invented by inventors of the second circle), we find some evidence to support it in the case of size and time, but not in the case of contractual funding, disciplines and institutions.

The results obtained so far, incline to be very prudent in indicating some systematic links between the sources of funding and the patent behavior. The disciplinary and legal frames related to the concerned activities are certainly more important than the origin of the funds. Actually, the role of disciplinary and institutional differences deserves some more attention:

* Disciplines tend to be more important to show differences within the first circle of inventors. The first two disciplines in terms of propensity to patent (biology and genetics) produce patents that will be either (co-)owned or not (co-)owned by ULP. However, the following one (physics) will focus on not (co-)owned patents, whereas medicine is more specialized in ULP (co-)owned patents. These results indicate at least that further research will have to be carried on to explain the process underway.

* Institutions tend to be more important to show differences between the first and the second circle of inventors. There is some evidence that inventors in the most prestigious laboratories (uins, umr, upr) tend to belong to the second circle: they do not patent through ULP, but through industry or other institutions (patnot_own2). These results are induced by institutional aspects: first the research units linked to CNRS or INSERM had (and have) a propensity to patent under the ownership of these Public Research Institutions, i.e. in this cases ULP do not always appear as coowner of the patent. Only upr, umr and uins are in this institutional configuration. It is partially due to the fact that ULP did not have its own independent IPR policy. Second CNRS and INSERM being national Public Research Institutions, and having active IPR policies, they were able to fund more often the patent deposit then the university. 


\section{Conclusion}

First, we found that ULP owned patents responds to contractual funding like aggregate US university owned patents responds to $\mathrm{R} \& \mathrm{D}$ expenditure. That is to say, they are responsive to regional and local public funding with decreasing returns to scale, and not to other sources of funding. We also provided some evidence showing that size of laboratories matters for ULP owned patenting whereas time effects do not. Whether these are (not necessarily undesirable) idiosyncrasies of using micro rather than macro evidence or a European/French rather than a US university should be subject to further research.

Second, we showed that it is important to control for disciplinary and institutional differences, since one or the other are significant for different kind of ULP patents. Implicitly we validate the use of laboratories as a unit of analysis, at least to estimate the returns of contractual funding on patents. Moreover, we give a first approximation to the link between disciplines and ownership and between institutions and circle of inventors of ULP patents.

Finally, we explored the convenience of not sticking to university owned patents in the analysis of university patents, since university non-owned patents have some different determinants, thus giving rise to different policy considerations. Beside the importance of disciplines and institutions, we saw different reactions to contractual funding, e.g. for ULP not (co-)owned patents invented by the first circle of inventors, only industrial funds matter. It is a sign that the observed patenting behavior is the result of the strategy of a trade-off: the external funding partner has generally also access to the property rights on the results.

A better understanding of the patent behavior of French university would at that stage imply a careful look into the legal and institutional dimensions of the links between university and external partners such as industry. For the comparisons with the US, it would in particular to look at the relation between the research sponsored by industry and the propensity to patents. 


\section{Acknowledgements}

This work is part of a larger project on knowledge production at ULP developed by a team of researchers at BETA. We are grateful to other members of the team for their support at some points (Caroline Hussler, Rachel Levy, Mireille Matt, Thuc Uyen Nguyen Thi, Musa Topaloglu, Panos Vassiliadis, and Sandrine Wolff). Acknowledgements should extend to the administrative services of the ULP, the TLO at the university (ULP-Industrie), and to the French patent office (INPI) for allowing us to get access their databases. We also thank Aldo Geuna for useful comments.

\section{Notes}

1. We use a broad notion of contractual funding, which includes not only funds from multilateral agreements but also from public calls for tenders, i.e. external funds, obtained through specific processes of competition, in particular private or public research programmes.

2. In France the revenues from patenting activity are shared among the inventor, the laboratory and the university.

3. Much attention has been paid to the effects of the Bayh-Dole Act in the US. For instance, from a sceptic's point of view, Mowery et al. (2001) argue that it just ratified a previous ongoing trend that would have given place to the explosion of university patenting anyway. In addition, Mowery and Sampat (2002) present some evidence that the Bayh-Dole Act made many incumbent universities start patenting less worthy inventions.

4. However, it may also have counter-productive impacts: Siegel et al. (2003), using the results of a survey of managers and scientists, report that one of the main objectives of TTO is the protection of property rights, although they tend to be "inflexible and conservative" when they negotiate agreements and licenses.

5. They are also interested in the methodological issue of finding an appropriate instrumental variable to avoid endogeneity problems and omitted input bias. They conclude that using alumni representation on US congressional appropriation committees improves the fit of the model. 
6. Three out of these 12 universities did not respond to the questionnaire but there was some available data from the AUTM reports.

7. Thursby and Kemp (2001) also tackle that issue using another econometric approach (efficiency analysis), although their conceptions of inputs and outputs are very similar.

8. There have been some studies about university patents in Europe, those mentioned in Section 2.1 on the Swedish case (Wallmark, 1997) and on the German case (Meyer-Krahmer and Schmoch, 1998), plus others on technology weaker countries, e.g. on the Italian case (Piccaluga, 2001; Balconi et al., 2002), and on a comparison between France, Italy and Spain (Cesaroni and Piccaluga, 2002). However, none of them apply econometric methods. An exception is Azagra et al. (2002), on a case study of a Spanish university.

9. For instance, there was no need for a Bayh-Dole Act because institutions always had the right to take intellectual property on publicly funded research.

10. The term "laboratory" is commonly used instead of "research unit". As we use a sample on the French case, we will talk of laboratories as well from now on.

11. Such external forces may be the strength of the TTO, legal changes, and contractual funding from other institutions.

12. Therefore, we could not look for patents invented by teaching and research staff not active in those years.

13. There is usually in France a very low turnover in teaching and research staff, therefore using the data of 1996 and 2000 allows for a large coverage in terms of teaching and research staff populations.

14. It should be noted that due to institutional arrangements between the University and both the CNRS and INSERM, research units research units which contracts we miss are limited to only a few of the ones supported by the CNRS and INSERM and are well identified.

15. It was available for 2000 as well, but since reliable data on patents ends the same year, we could not use that information. 
16. Therefore, it does not include other financial resources such as payrolls, current expenditure or purchase of equipment charged to the university budget. However, a proxy variable of all these is our measure of size.

17. The case of medicine is certainly also the sign of a weakness in the data base, due to institutional reasons. The research done in that field is strongly inter-connected with the University Hospital (which is a separate and independent institution in our case). It is then more difficult to have reliable information about the personnel and as a consequence about the patents invented by unreported personnel.

\section{References}

Adams, J., and Z. Griliches, 1998, 'Research Productivity in a System of Universities,' Annales d'Economie et de Statistique, 49/50, 127-162.

Agrawal, A., and R. Henderson, 2002, 'Putting Patents in Context: Exploring Knowledge Transfer from MIT,' Management Science, 48 (1), 44-60.

Azagra, J., I. Fernández, and A. Gutiérrez, 2003, 'University Patents: Output and Input Indicators... of What?,' Research Evaluation 12 (1): 5-16.

Arora, A., P.A. David and A. Gambardella, 1998, 'Reputation and Competence in Publicly Funded Science: Estimating the Effects on Research Group Productivity,' Annales d'Economie et de Statistique 49/50, 163-198.

Balconi, M., S. Breschi and F. Lissoni, 2002, 'Networks of Inventors and the Location of University Research: An Exploration of Italian Data,' conference 'Rethinking Science Policy', SPRU, University of Sussex, Brighton, 21-23 March.

Blumenthal, M.D., E.G. Campbell, M. Anderson, N. Causino and K.S. Louis, 1997, 'Withholding Research Results in Academic Life Science: Evidence from a National Survey of Faculty,' Journal of the Academic Medical Association 277 (15), 1224-1228. 
Blumenthal, M.D., N. Causino, E.G. Campbell and K.S. Louis, 1996, 'Participation of Life-Science Faculty in Research Relationships with Industry,' The New England Journal of Medicine 335 (23), 1734-1739.

Carlsson, B. and A.C. Fridh, 2002, 'Technology Transfer in the United States Universities,' Journal of Evolutionary Economics 12, 199-232.

Cesaroni, F. and A. Piccaluga, 2002, 'Patenting Activities of European Universities. Relevant? Growing? Useful?,' conference 'Rethinking Science Policy', SPRU, University of Sussex, Brighton, 21-23 March.

Cohen W.M., R. Florida and W.R. Goe, 1994, 'University-Industry Research Centers in the United States,' Carnegie Mellon University, Pittsburgh.

Cohen W.M., R. Florida, L. Randazzese and J. Walsh, 1998, 'Industry and the Academy: Uneasy Partners in the Cause of Technological Advance', in R. Noll (ed.), Challenge to the university, Washington DC: Brookings Institution Press, pp. 171-199.

Coupé, T., 2003, 'Science is Golden: Academic R\&D and University Patents,' Journal of Technology Transfer 28, 31-46.

Crow, M. and B. Bozeman, 1987, 'R\&D Laboratory Classification and Public Policy: The Effects of Environmental Context on Laboratory Behavior,' Research policy 16, 229-258.

Foltz, J., B. Barham and K. Kim, 2000, 'Universities and Agricultural Biotechnology Patent Production,' Agribusiness 16 (1), 82-95.

Foltz, J., K. Kim and B. Barham, 2001, ‘A Dynamic Count Data Analysis of University Ag-Biotech Patents,' Food Marketing Policy Center Research Report 56.

Green, W. H., 2003, Econometric Analysis, Prentice Hall, 5th edition.

Griliches, Z., 1990, 'Patent Statistics as Economic Indicators: A Survey,' Journal of Economic Literature XXVIII, 1661-707. 
Hausman, H., B.H. Hall and Z. Griliches, 1984, 'Econometric Models for Count Data with an Application to the Patents-R\&D Relationship,' Econometrica 52 (4), 909-938.

Henderson, R., A.B. Jaffe and M. Trajtenberg, 1998, 'Universities as a Source of Commercial Technology: A Detailed Analysis of University Patenting, 1965-1988,' Review of Economics and Statistics $80(1), 119-27$.

Jaffe, A. B., 2000, 'The U.S. patent system in transition: policy innovation and the innovation process', Research policy 29: 531-557.

Joly, P.B. and V. Mangematin, 1996, 'Profile of Public Laboratories, Industrial Partnerships and Organization of R\&D: The Dynamics of Industrial Relationships in a Large Research Organization,' Research Policy 25, 901-922.

Meyer, M., 2002, 'Do Patents Reflect the Inventive Output of University Research?,' mimeo KU Leuven, Finnish Institute for Enterprise Management, Helsinki.

Meyer-Krahmer, F. and U. Schmoch, 1998, 'Science-Based Technologies: University-Industry Interactions in Four Fields,' Research Policy 27 (8), 835-51.

Mowery, D.C., R.R. Nelson, B.N. Sampat and A.A. Ziedonis, 2001, 'The Effects of Patenting and Licensing by U.S. Universities: an Assessment of the Effects of the Bayh-Dole Act of 1980,' Research Policy 30, 99-119.

Mowery, D.C. and B.N. Sampat, 2001, 'Patenting and Licensing University Inventions: Lessons from the History of the Research Corporation,' Industrial and Corporate Change 10 (2), 317-355.

Mowery, D.C. and A.A. Ziedonis, 2002, 'Academic Patent Quality Before and After the Bayh-Dole Act in the United States,' Research Policy 31, 399-418.

Nelson, R.R., 2001, 'Observations on the Post-Bayh-Dole Rise in University Patenting,' Journal of Technology Transfer 26 (1/2), 13-19.

Pavitt, K., 1998, 'Do Patents Reflect the Useful Research Output of Universities?,' Research evaluation 7 (2), 105-11. 
Payne, A.A. and A. Siow, 2003, 'Does Federal Research Funding Increase University Research Output?,' Advances in Economic Analysis \& Policy 3 (1), Article 1.

Piccaluga, A., 2001, La Valorizzazione della Ricerca Scientifica, Milano: Franco Angeli.

Rappert, B., A. Webster and D. Charles, 1999, 'Making Sense of Diversity and Reluctance: Academic-Industrial Relations and Intellectual Property,' Research Policy 28, 873-890.

Saragossi, S. and B. van Pottelsberghe de la Potterie, 2003, 'What Patent Data Reveal about Universities: The Case of Belgium,' Journal of Technology Transfer, 18, 47-51.

Siegel, D., D. Waldman and A. Link, 2003, 'Assessing the Impact of Organizational Practices on the Productivity of University Technology Transfer Offices: An Exploratory Study,' Research Policy $28,27-48$.

Stephan, P. and S. Levin, 1997, 'The Critical Importance of Careers in Collaborative Scientific Research”, Revue d'Economie Industrielle 79 (1), 45-61.

Thursby, J. and L. Kemp, 2002, 'Growth and Productive Efficiency of University Intellectual Property Licensing,' Research Policy 31, 109-124.

Wallmark, J. T., 1997, 'Innovations and Patents at Universities: the Case of Chalmers University of Technology,' Technovation 17 (3), 127-39. 
Appendix

Table 1. Descriptive statistics of variables in the model

\begin{tabular}{|c|c|c|c|c|}
\hline Variable & Description & Mean & Standard Error & Share of patents \\
\hline Pat & Number of ULP patents & 0.70 & 1.65 & \\
\hline Patown & $\begin{array}{l}\text { Number of ULP (co-)owned } \\
\text { patents by first circle of inventors }\end{array}$ & 0.09 & 0.44 & \\
\hline Patnon_own1 & $\begin{array}{l}\text { Number of ULP non-(co-)owned } \\
\text { patents by first circle of inventors }\end{array}$ & 0.23 & 0.86 & \\
\hline Patnon_own2 & $\begin{array}{l}\text { Number of ULP non-(co-)owned } \\
\text { patents by second circle of } \\
\text { inventors }\end{array}$ & 0.37 & 1.15 & \\
\hline Cont & $\begin{array}{l}\text { Logarithm of real value of } \\
\text { contractual funding... }\end{array}$ & 3.05 & 2.90 & \\
\hline Nat & with national government & 0.41 & 1.43 & \\
\hline Reg & $\begin{array}{l}\text { with regional and local } \\
\text { governments }\end{array}$ & 0.60 & 1.70 & \\
\hline Eur & with European government & 0.86 & 2.04 & \\
\hline Ind & with industry & 1.84 & 2.62 & \\
\hline Prc & with public research centers & 1.34 & 2.36 & \\
\hline As & with associations & 0.50 & 1.56 & \\
\hline Dcont & $\begin{array}{l}\text { CNRS or INSERM unit that reports } \\
\text { no contracts in a given year }\end{array}$ & 0.24 & 0.43 & \\
\hline Size & $\begin{array}{l}\text { Size categories of number of } \\
\text { faculty }\end{array}$ & 1.41 & 1.13 & \\
\hline Disc & Discipline & & & \\
\hline Bio & Biology & 0.14 & 0.35 & $22.68 \%$ \\
\hline Che & Chemistry & 0.10 & 0.30 & $8.21 \%$ \\
\hline Gen & Genetics & 0.11 & 0.31 & $36.72 \%$ \\
\hline Med & Medicine & 0.27 & 0.44 & $7.56 \%$ \\
\hline $\mathrm{Neu}$ & Neurology & 0.08 & 0.28 & $0.86 \%$ \\
\hline $\mathrm{Ph}$ & Physics & 0.06 & 0.24 & $11.02 \%$ \\
\hline Others & $\begin{array}{l}\text { Exact sciences (except } \\
\text { physics) and social sciences } \\
\text { and humanities }\end{array}$ & 0.24 & 0.43 & $12.96 \%$ \\
\hline Inst & Institutions & & & \\
\hline Uins & INSERM unit & 0.11 & 0.31 & $6.48 \%$ \\
\hline Upr & CNRS unit & 0.25 & 0.44 & $54.64 \%$ \\
\hline Umr & $\begin{array}{l}\text { Joint unit (ULP-CNRS or ULP- } \\
\text { INSERM) }\end{array}$ & 0.23 & 0.42 & $24.62 \%$ \\
\hline Others & Less prestigious units & 0.13 & 0.34 & $14.26 \%$ \\
\hline Time & Trend & 96.50 & 2.29 & \\
\hline
\end{tabular}


Table 2 . Negative binomial estimation of ULP patents -reduced models

\begin{tabular}{|c|c|c|c|}
\hline Indep. Var.I Dep. Var. & Patown & $\begin{array}{l}\text { Patnon_own1 (zero } \\
\text { inflated estimation) }\end{array}$ & Patnon_own2 \\
\hline Constant & $-6,76(0,95) * *$ & $-4,81(0,94) * *$ & $-3,58(0,67)$ ** \\
\hline \multicolumn{4}{|l|}{ (Cont) } \\
\hline \multicolumn{4}{|l|}{ Nat } \\
\hline Reg & $0,26(0,12)$ * & & \\
\hline \multicolumn{4}{|l|}{ Eur } \\
\hline Ind & & $0,21(0,08)$ ** & \\
\hline \multicolumn{4}{|l|}{ Prc } \\
\hline \multicolumn{4}{|l|}{ As } \\
\hline \multicolumn{4}{|l|}{ Dcont } \\
\hline Size & $0,74(0,31)$ * & $1,34(0,38)$ ** & $0,34(0,13)$ ** \\
\hline \multicolumn{4}{|l|}{ (Disc) } \\
\hline Bio & $4,34(0,89) * *$ & $3,94(0,77)$ ** & $-0,11(0,58)$ \\
\hline Che & $1,86(1,02)$ & $1,06(0,85)$ & $0,09(0,41)$ \\
\hline Gen & $3,75(0,84)$ ** & $3,84(0,92)$ ** & $0,74(0,49)$ \\
\hline Med & $2,7(0,96) * *$ & $0,95(0,89)$ & $-1,55(0,7)$ * \\
\hline $\mathrm{Neu}$ & $2,01(1,08)$ & $0,03(1,51)$ & $-2,76(1,16)$ * \\
\hline $\mathrm{Ph}$ & $1,85(1,32)$ & $6,84(1,64) * *$ & $0,6(0,55)$ \\
\hline \multicolumn{4}{|l|}{ (Inst) } \\
\hline Uins & & $-1,01(0,93)$ & $3,37(0,46) * *$ \\
\hline Upr & & $-1,95(0,77)$ * & $2,62(0,54)$ ** \\
\hline Umr & & $-1,88(0,75)$ * & $1,57(0,69)$ * \\
\hline Time & $3,45(1,68)$ * & $0,96(0,46)$ * & $2,07(0,46) * *$ \\
\hline$\delta$ & & $0,68(0,31)$ * & \\
\hline$p$ & & $-1,88(0,75)$ * & $1,57(0,69)$ * \\
\hline No. of observations & 664 & 664 & 664 \\
\hline Log likelihood & $-162,07$ & $-285,46$ & $-391,00$ \\
\hline Restricted log likelihood & $-175,83$ & & $-454,25$ \\
\hline Chi-squared & 27,5 ** & & 126,51 ** \\
\hline Degrees of freedom & 9 & 13 & 11 \\
\hline
\end{tabular}

Standard errors in brackets. The number of asterisks (one or two) denotes the level of significance of the coefficients (5 or 1 percent, respectively).

${ }^{\mathrm{i}}$ There are also some other determinants of university patenting. Foltz et al (2001) include a measure of faculty quality (average wage), that they find significantly positive. The same happens to Coupé (2003). Foltz et al. (2001) include a measure of patenting experience (accumulated number of past patents) and they find it significantly positive, so they predict difficulties for lagging universities to catch-up. Coupé (2003) makes a distinction between public and private universities but he does not find significant differences. Foltz et al. (2000) find that the presence of agricultural schools and the importance of agriculture in the local economy help explaining the production of agricultural biotechnology university patents.

${ }^{i i}$ For technical details, see Greene (2003), section 21.9. 
iii We also tried with time dummies instead of a time trend, but results were identical.

${ }^{\text {iv }}$ We could wonder whether dcont is correlated with upr and/or uins. The coefficients of correlation are not high, though ( 0.54 and 0.35 respectively). Besides, as we will show in the results, we can drop dcont in the regressions without any change.

${ }^{\mathrm{v}}$ In every case, we will use pooled panel technique. 